\title{
RANCANG BANGUN PHONOCARDIOGRAF BERBASIS LABVIEW
}

\author{
Ramdani Febrian ${ }^{1}$, Budi Sumanto ${ }^{2 *}$ \\ ${ }^{1,2}$ Departemen Teknik Elektro dan Informatika, Sekolah Vokasi, Universitas Gadjah Mada \\ ramdanifebrian@gmail.com ${ }^{1}$,bs.jogja@gmail.com ${ }^{2}$ \\ (*) Corresponding Author
}

\begin{abstract}
The aim of this research is to develop a phonocardiograph system to display the signal and information form of the human heart sound examination. The analytical method applied is to use the Fast Fourier Transform (FFT) to determine the frequency of responses of human heart sound signals by using Labview software. The results obtained indicate the system able to display the signal shape of the heart sound, based on ten respondents whose data are taken shows the range of heart sound frequencies is in the range of 145 to $225 \mathrm{~Hz}$ with a duration of 81 to $120 \mathrm{bpm}$.
\end{abstract}

Keywords: Phonocardiograph, FFT, Labview

Intisari - Tujuan dari penelitian ini adalah membangun sistem phonocardiograf untuk menampilkan bentuk sinyal dan informasi dari pemeriksaan suara jantung manusia. Metode analisis yang diterapkan adalah menggunakan Fast Fourier Transform (FFT) untuk mengetahui frekuensi respon dari sinyal suara jantung manusia dengan memanfaatkan perangkat lunak Labview. Hasil yang diperoleh menunjukkan sistem mampu menampilkan bentuk sinyal dari suara jantung, berdasarkan sepuluh responden yang diambil datanya menunjukkan rentang frekuensi suara jantung berada pada rentang 145 s.d $225 \mathrm{~Hz}$ dengan durasi 81 s.d 120 bpm.

Kata kunci : Phonocardiograf, FFT, Labview

\section{PENDAHULUAN}

Pemeriksaan kesehatan jantung biasanya dilakukan oleh dokter atau paramedic dengan mendengarkan suara detak jantung dengan menggunakan stetoskop. Biasanya hasil pemeriksaan hanya berupa informasi detak jantung per menitnya yang berarti sinyal suara jantung tersebut berada pada domain waktu.

Pengembangan teknologi informasi kesehatan suara jantung tidak lagi mengandalkan informasi detak jantung saja tetapi sinyal suara jantung tersebut direkam dan diubah ke dalam domain frekuensi, hal ini bisa dijadikan bahan analisis untuk mengetahui kondisi kesehatan jantung seorang pasien, apakah jantung tersebut normal atau tidak, dan juga bisa diketahui heart beat rate (jumlah detak jantung per menit) dari pasien tersebut, yang berguna untuk mengetahui seberapa cepat detak jantung seseorang, dan juga dapat diketahui heart beat indicatornya, yaitu indikasi jantung berdetak dengan diberikannya LED indikator [1].

Hasil pemeriksaan untuk suara yang sama bisa diartikan berbeda oleh dokter lain, itu dikarenakan berbedanya pengalaman, kualitas alat yang digunakan dan kepekaan telinga yang dimiliki oleh seorang dokter dalam melakukan pemeriksaan. Dengan adanya sistem penampil, perbedaan ini bisa diseragamkan. Selain itu, dengan adanya sistem penampil bisa dijadikan bahan pembelajaran serta bahan diskusi bersama dokter-dokter lain [2].

\section{LANDASAN TEORI}

\section{A. Phonecardiography}

Auskultasi adalah teknik mendengarkan suara yang dihasilkan oleh organ tubuh, dari yang menggunakan metode langsung menempelkan telinga ke organ tubuh, sampai dengan menggunakan alat bantu dengar (stetoskop). Sedangkan Phonocardiography merujuk pada ilmu penelusuran suara jantung dan pencatatan getaran akustik jantung menggunakan sensor suara, pada artikel ini, mikrofon elekret digunakan sebagai sensor suaranya, sedangkan phonocardiogram (pcg) adalah hasil dari perekaman suara jantung tersebut, dan heart sound adalah istilah lain dari hasil objek ukur suara jantung, yang dalam bahasa Indonesia disebut suara jantung [3]. Gambar 1 berikut ini menunjukkan gambaran dari phonocardiogram.

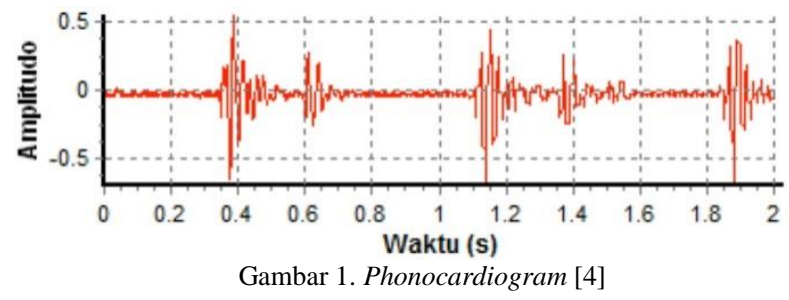

\section{B. Fast Fourier Transform (FFT)}

Fast Fourier Transform adalah suatu algoritma yang digunakan untuk merepresentasikan sinyal dalam domain waktu diskrit dan domain frekuensi. Domain waktu diskrit (Periode) didefinisikan sebagai waktu yang dibutuhkan sebuah isyarat atau gelombang untuk mencapai suatu gelombang penuh dan dapat menentukan nilai periodesitasnya. Perlu dicermati bahwa pengertian ini berlaku untuk isyarat monokromatis, isyarat yang dimaksud adalah gelombangnya bersifat tunggal dan pasti memiliki sebuah priode. Dengan demikian isyarat itu dikenal dengan istilah priodis. Pengamatan dapat dilakukan dengan memantau gelombang sehingga dapat diketahui nilai yang terkandung dalam isyarat serta periodenya [1].

Domain frekuensi diartikan sebagai jumlah gelombang yang terjadi dalam 1 detik. Frekuensi didefinisikan secara sederhana sebagai kebalikan dari waktu. Sehingga waktu 
yang satuannya adalah detik (second) akan menjadi Hertz (1-per second), hanya akan memiliki tepat satu nilai spektrum yang dikenal dengan spektrum frekuensi.

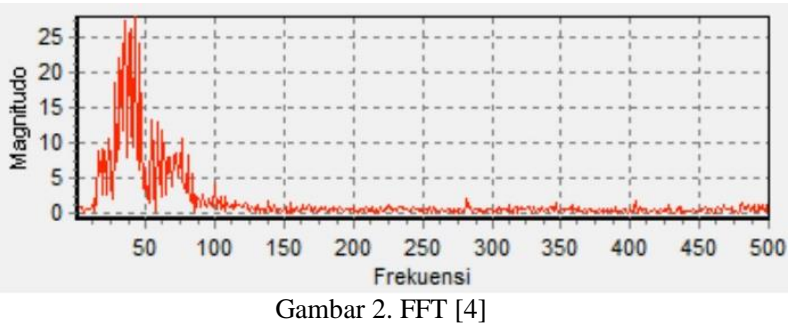

Gambar 2 memberikan gambaran terkait FFT. Adapun proses untuk mendapatkan nilai FFT tersebut berasal dari persamaan (1).

$$
X(f)=\int x(t) e^{-j 2 \Pi f t}
$$

Berdasarkan persamaan (1) diketahui $t$ adalah parameter waktu, sedangkan $\mathrm{f}$ adalah parameter frekuensi, sinyal domain waktu $x(t)$ dikalikan dengan eksponensial kompleks pada frekuensi $f$ dan diintegralkan dengan waktu keseluruhan.

\section{Heart-beat rate}

Heart-beat rate adalah kecepatan detak jantung yang diukur dari seberapa banyak jantung berdetak dalam satu menit dengan satuan beat per minute (bpm). Kecepatan detak jantung seseorang berbeda-beda tergantung kondisi fisik seseorang. Kecepatan tersebut bisa dipengaruhi oleh olahraga, tidur, gelisah, stres, penyakit dan mengkonsumsi obat - obatan. Jumlah detak jantung normal adalah 60150bpm, lebih dari 150 adalah tachycardia (detak jantung cepat) dan kurang dari 60 adalah bradycardia (detak jantung lambat) [5].

\section{METODOLOGI PENELITIAN}

\section{A. Perancangan Sistem}

Perancangan sistem dari sistem penampil isyarat suara jantung dibagi menjadi 2 bagian, yaitu perangkat keras (hardware) dan perangkat lunak (software). Perangkat keras meliputi stetoskop elektronik yaitu penggabungan stetoskop dengan mikrofon elektret sebagai pendeteksi suara jantung, pembuatan rangkaian stetoskop sebagai pengendali mikrofon, agar mikrofon dapat bekerja dengan normal dan pemberi penguatan awal agar data dapat terbaca di komputer. Perangkat lunak meliputi penggunaan software audacity sebagai perekam, pemberi penapis suara jantung dan pemberi penguatan agar data dapat ditampilkan di Labview. Selanjutnya, software Labview akan memutar ulang hasil rekaman serta menampilkan gelombang suara jantungnya kemudian mengonversi gelombang tersebut ke domain frekuensi (FFT) serta menampilkan fitur heart-beat rate \& heartbeat indicator. Gambar 3 merupakan blok diagram sistem.

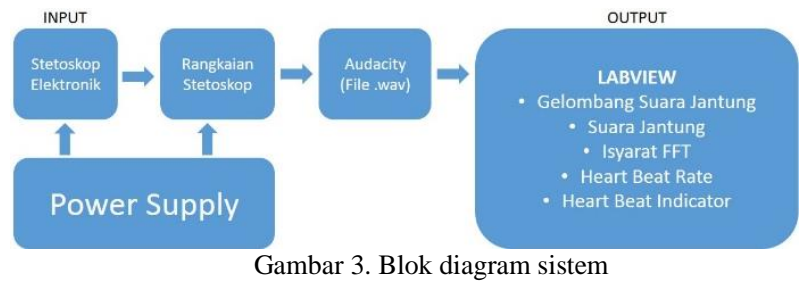

B. Perancangan perangkat keras (hardware)

Perangkat keras (hardware) sistem penampil isyarat suara jantung terdiri dari stetoskop elektronik dan rangkaian stetoskop.

1) Stetoskop elektronik

Gambar 4 merupakan gambaran stetoskop elektronik.

\section{STETOSKOP ELEKTRONIK}

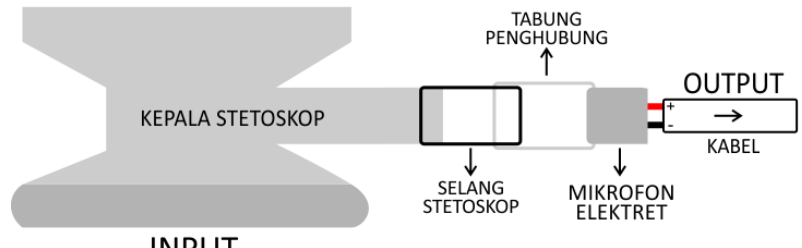

Gambar 4. Stetoskop elektronik

Stetoskop elektronik terdiri dari gabungan kepala stetoskop dengan mikrofon elektret, yang dimana ujung kepala stetoskop disatukan dengan mikrofon menggunakan tabung penghubung. Data keluaran dari mikrofon kemudian disalurkan ke rangkaian stetoskop, melalui kabel mic dengan panjang $\pm 50 \mathrm{~cm}$, mikrofon yang digunakan berjenis elektret dengan tipe 2 pin (+,-), yang memiliki diameter $9 \mathrm{~mm}$, dan respons frekuensi 0-1000hz.

2) Rangkaian stetoskop

Rangkaian stetoskop adalah rangkaian yang berfungsi sebagai pemberi arus yang sesuai dengan mikrofon elekret agar mikrofon dapat bekerja dengan normal dan sebagai pemberi penguatan awal agar data dapat terbaca di komputer. Gambar 5 merupakan gambaran dari rangkaian stetoskop.

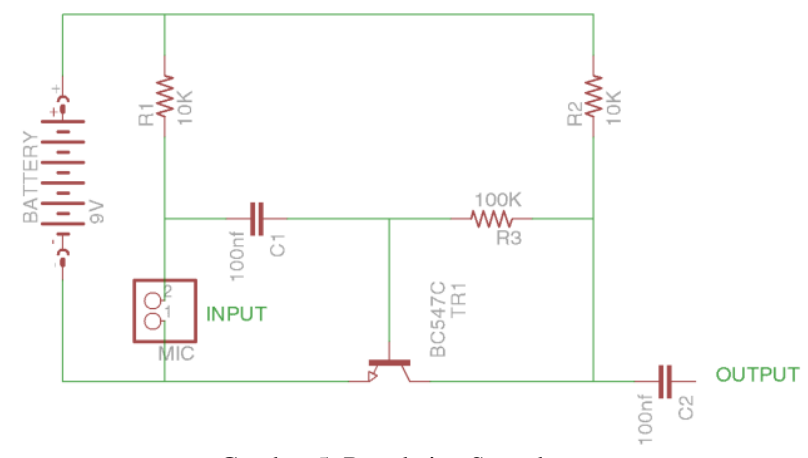

Gambar 5. Rangkaian Stetoskop

Rangkaian stetoskop ini, terdiri dari 2 jenis rangkaian, yaitu rangkaian mic, dan rangkaian pre-amp. Rangkaian mic terdiri dari R1 dan $\mathrm{C} 1$. R1 berfungsi sebagai pengatur arus agar arus yang masuk ke mic sesuai dengan yang dibutuhkan. $\mathrm{C} 1$ berfungsi sebagai $A C$ coupling, yaitu agar sinyal audio yang dikeluarkan mic dapat terbaca dengan baik. Setelah keluar dari $\mathrm{C} 1$, sinyal akan masuk ke 
rangkaian pre-amp sebagai penguat awal. Kemudian sinyal akan masuk ke basis transistor. Fungsi R2 dan R3 sendiri adalah sebagai pengatur penguatannya. Setelah sinyal dikuatkan, sinyal akan keluar melalui C2. Fungsi C2 sama dengan $\mathrm{C} 1$, yaitu sebagai $A C$ coupling. Keluaran dari rangkaian ini akan masuk ke soundcard melalui jack audio.

\section{Perancangan perangkat lunak (software)}

Perancangan perangkat lunak terdiri dari penggunaan software audacity sebagai perekam suara jantung, pemberi penguatan dan penapisan, serta penggunaan software Labview sebagai penampil akhir, yang menampilkan suara dan sinyalnya, isyarat FFT, heart-beat rate dan heart-beat indicator. Gambar 6 merupakan flowchart dari sistem penampil isyarat suara jantung.

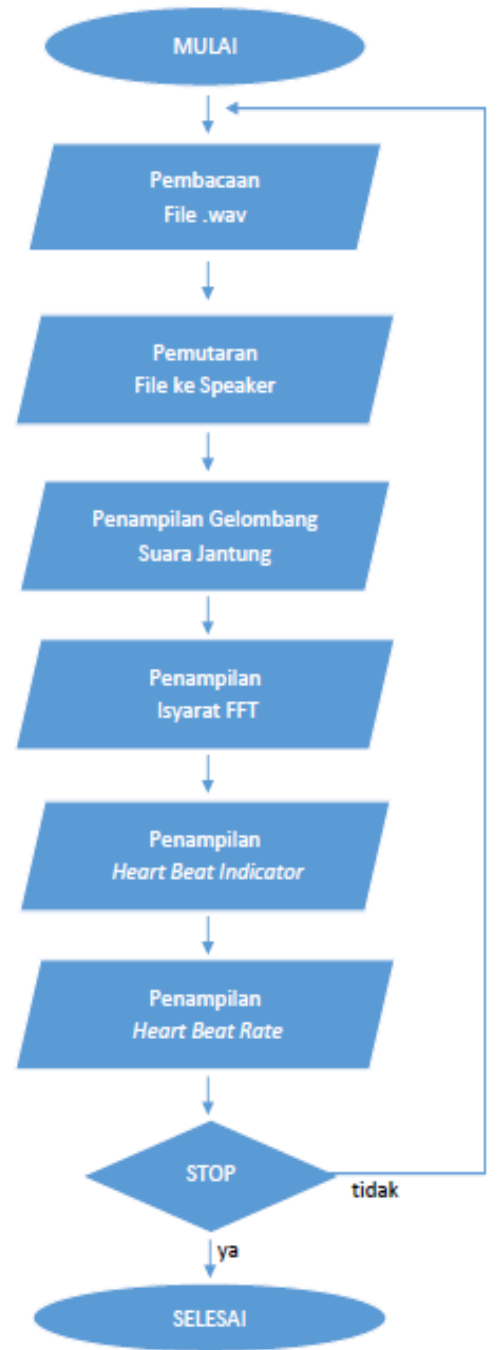

Gambar 6. Flowchart Sistem Penampil

\section{HASIL DAN ANALISIS}

A. Hasil dan Analisis

Variabel yang dijadikan pembahasan dalam artikel ini ada dua, yaitu frekuensi dari S1 (suara jantung pertama), dan heart-beat rate (jumlah detak jantung per menit). Pengambilan data dilakukan dalam kondisi rileks atau santai dengan menggunakan sampling rate $44100 \mathrm{hz}$. Tabel 1 merupakan data hasil isyarat suara jantung yang dilakukan terhadap 10 responden sedangkan Gambar 7 merupakan data hasil dari sistem penampil isyarat suara jantung.

Tabel 1. Tabel Data Hasil Isyarat Suara Jantung

\begin{tabular}{ccc}
\hline No & $\begin{array}{c}\text { Frekuensi S1 } \\
(\mathrm{hz})\end{array}$ & $\begin{array}{c}\text { Heart-beat Rate } \\
(\mathrm{bpm})\end{array}$ \\
\hline 1 & 200 & 85 \\
2 & 200 & 92 \\
3 & 225 & 100 \\
4 & 215 & 100 \\
5 & 190 & 92 \\
6 & 200 & 81 \\
7 & 190 & 120 \\
8 & 150 & 100 \\
9 & 160 & 92 \\
10 & 145 & 90 \\
\hline
\end{tabular}

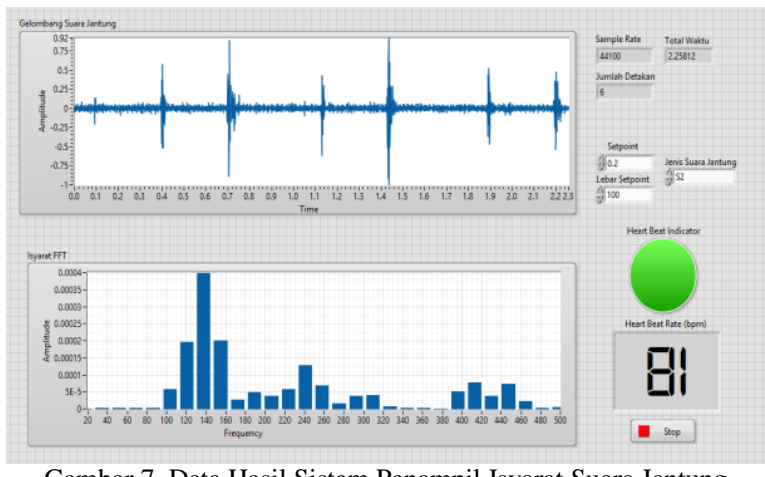

Gambar 7. Data Hasil Sistem Penampil Isyarat Suara Jantung

Data hasil yang ditampilkan pada gambar 7 merupakan data hasil dari salah satu responden pengukuran suara jantung. Diketahui dari enam suara yang terdeteksi, frekuensi suara jantung pertama berada pada frekuensi $200 \mathrm{hz}$ dengan heart beat rate-nya adalah $81 \mathrm{bpm}$.

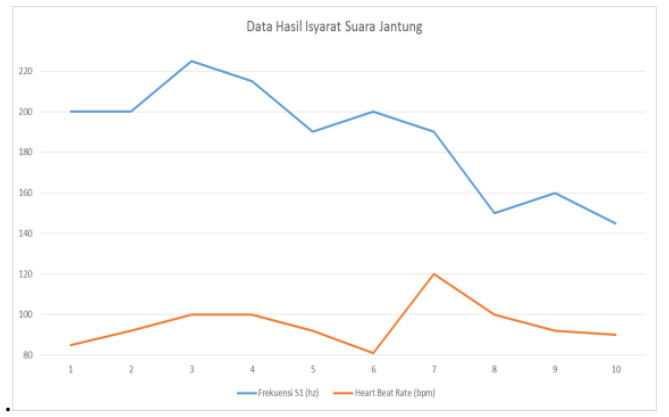

Gambar 8. Grafik Data Hasil Pengukuran Isyarat Suara Jantung

Gambar 8 merupakan grafik data hasil pengukuran isyara suara jantung dari sepuluh orang responden. Diketahui dari 10 responden pada gambar 8, untuk pendeteksian frekuensi S1 diketahui berada pada rentang 145-225Hz. Hal ini terbukti benar berdasarkan teori [6] yang mengatakan bahwa frekuensi S1 berada pada frekuensi $125-300 \mathrm{hz}$. Untuk heart-beat rate 10 responden berada pada rentang 81-120bpm dan dikategorikan heartbeat rate normal berdasarkan teori [5] yang mengatakan bahwa heart beat rate normal adalah $60-150 \mathrm{bpm}$. 


\section{PENUTUP}

\section{Kesimpulan}

Berdasarkan hasil penelitian ini dapat disimpulkan bahwa sistem dapat bekerja sesuai dengan apa yang diharapkan yaitu mampu menampilkan gelombang suara jantung sekaligus nilai detak per menitnya serta frekuensi responnya. Berdasarkan sepuluh responden diketahui rentang frekuensi suara jantung berada pada frekuensi 145 s.d $225 \mathrm{~Hz}$, dengan rentang nilai bpmnya adalah 81-120 bpm.

\section{DAFTAR PUSTAKA}

[1] Debbal, S.M., Reguig, F.B., 2008, Frequency Analysis of the Heartbeat Sounds, Department of Electronic, Faculty of Science Engineering, University Aboubekr Belkaid, Algeria

[2] Suardi, Wibowo, E.M., Januarifin W., Subakir, I., Wahidin, A.M., 2007, Visualisasi Isyarat Detak Jantung Berbasis Komputer, Prodi T. Elektro, Fak. T. Industri, UAD, Yogyakarta

[3] Cromwell, L., Weibell, F.J., Pfeiffer, E.A., Usselman, L.B., 1973, Biomedical Instrumentation \& Measurements, Prentice-hall.inc, Englewood Cliffs, New Jersey

[4] Suprayitno, E.A., dan Anshory, I., Sistem Instrumentasi Sinyal Phonocardiography untuk Analisa Dinamika Jantung, UMS, Sidoarjo

[5] Setiaji, F.D., Santoso, D., Susilo, D., 2011, Rekayasa Stetoskop Elektronik dengan Kemampuan Analisis Bunyi Jantung, Prodi Teknik Elektro, UKSW, Salatiga

[6] Thinkslab Medical LLC, 2015, thinklabs.com, America 